\title{
Universiteit
}

Leiden

The Netherlands

\section{High yield of B-branch electron transfer in a quadruple reaction center mutant of the photosynthetic bacterium Rhodobacter sphaeroides}

Boer, A.L. de; Neerken, S.; Wijn, R. de; Permentier, H.P.; Gast, P.; Vijgenboom, E.; Hoff, A.J.

\section{Citation}

Boer, A. L. de, Neerken, S., Wijn, R. de, Permentier, H. P., Gast, P., Vijgenboom, E., \& Hoff, A. J. (2002). High yield of B-branch electron transfer in a quadruple reaction center mutant of the photosynthetic bacterium Rhodobacter sphaeroides. Biochemistry, 41(9), 3081-3088. doi:10.1021/bi011450m

Version: $\quad$ Publisher's Version

License: $\quad$ Licensed under Article 25fa Copyright Act/Law (Amendment Taverne)

Downloaded from: https://hdl.handle.net/1887/3239465

Note: To cite this publication please use the final published version (if applicable). 


\title{
High Yield of B-Branch Electron Transfer in a Quadruple Reaction Center Mutant of the Photosynthetic Bacterium Rhodobacter sphaeroides ${ }^{\dagger}$
}

\author{
Arjo L. de Boer, ${ }^{\ddagger}$ Sieglinde Neerken, ${ }^{\ddagger}$ Rik de Wijn, ${ }^{\ddagger}$ Hjalmar P. Permentier, ${ }^{\ddagger}$ Peter Gast,,${ }^{\ddagger}$ Erik Vijgenboom, ${ }^{\S}$ and \\ Arnold J. Hoff*, \\ Department of Biophysics, Huygens Laboratory, and Leiden Institute of Chemistry, Gorlaeus Laboratories, Leiden University, \\ Post Office Box 9504, 2300 RA Leiden, The Netherlands
}

Received July 12, 2001; Revised Manuscript Received November 20, 2001

\begin{abstract}
A new reaction center (RC) quadruple mutant, called LDHW, of Rhodobacter sphaeroides is described. This mutant was constructed to obtain a high yield of B-branch electron transfer and to study $\mathrm{P}^{+} \mathrm{Q}_{\mathrm{B}}{ }^{-}$formation via the $\mathrm{B}$-branch. The A-branch of the mutant $\mathrm{RC}$ contains two monomer bacteriochlorophylls, $\mathrm{B}_{\mathrm{A}}$ and $\beta$, as a result of the $\mathrm{H}$ mutation $\mathrm{L}(\mathrm{M} 214) \mathrm{H}$. The latter bacteriochlorophyll replaces bacteriopheophytin $\mathrm{H}_{\mathrm{A}}$ of wild-type RCs. As a result of the $\mathrm{W}$ mutation $\mathrm{A}(\mathrm{M} 260) \mathrm{W}$, the A-branch does not contain the ubiquinone $\mathrm{Q}_{\mathrm{A}}$; this facilitates the study of $\mathrm{P}^{+} \mathrm{Q}_{\mathrm{B}}{ }^{-}$formation. Furthermore, the $\mathrm{D}$ mutation G(M203)D introduces an aspartic acid residue near $B_{A}$. Together these mutations impede electron transfer through the A-branch. The B-branch contains two bacteriopheophytins, $\Phi_{\mathrm{B}}$ and $\mathrm{H}_{\mathrm{B}}$, and a ubiquinone, $\mathrm{Q}_{\mathrm{B} .} \Phi_{\mathrm{B}}$ replaces the monomer bacteriochlorophyll $\mathrm{B}_{\mathrm{B}}$ as a result of the $\mathrm{L}$ mutation $\mathrm{H}(\mathrm{M} 182) \mathrm{L}$. In the LDHW mutant we find 35-45\% B-branch electron transfer, the highest yield reported so far. Transient absorption spectroscopy at $10 \mathrm{~K}$, where the absorption bands due to the $\mathrm{Q}_{\mathrm{X}}$ transitions of $\Phi_{\mathrm{B}}$ and $\mathrm{H}_{\mathrm{B}}$ are well resolved, shows simultaneous bleachings of both absorption bands. Although photoreduction of the bacteriopheophytins occurs with a high yield, no significant $(\sim 1 \%) \mathrm{P}^{+} \mathrm{Q}_{\mathrm{B}}{ }^{-}$formation was found.
\end{abstract}

Despite the fact that the reaction center $(\mathrm{RC})^{1}$ of purple photosynthetic bacteria has two symmetrically arranged branches of cofactors, labeled $\mathrm{A}$ and $\mathrm{B}$, that in principle could be used in charge separation, only one of them, branch A, is actually used. This is a conserved feature of RCs of purple bacteria and has also been found for the RC of the green filamentous bacterium Chloroflexus aurantiacus. Evidence for the preferential use of only one of the two branches comes primarily from studies on the bleaching of the absorption bands of the bacteriopheophytins $\mathrm{H}_{\mathrm{A}}$ and $\mathrm{H}_{\mathrm{B}}$ at cryogenic temperatures. At room temperature these bands overlap, but at cryogenic temperatures both the $\mathrm{Q}_{\mathrm{X}}$ and the $\mathrm{Q}_{\mathrm{Y}}$ absorption bands of the bacteriopheophytins become (more) resolved. Linear dichroism studies on single crystals from Rhodopseudomonas viridis $\mathrm{RCs}(1)$ and mutagenesis studies on RCs from Rhodobacter capsulatus (2) and Rhodobacter sphaeroides (3) have shown that the bacteriopheophytin used in charge separation is $\mathrm{H}_{\mathrm{A}}$. Both the $\mathrm{Q}_{\mathrm{X}}$ and the $\mathrm{Q}_{\mathrm{Y}}$ bands of $\mathrm{H}_{\mathrm{A}}$ are red-shifted relative to the corresponding bands of $\mathrm{H}_{\mathrm{B}}$ for RCs of Rb. sphaeroides, Rb. capsulatus, Rps. viridis,

\footnotetext{
${ }^{\dagger}$ H.P.P. and R.d.W. acknowledge support from the Chemistry Division of The Netherlands Organization for Scientific Research (NWO)

* Author to whom correspondence should be addressed: phone +31 71-5275955; fax +31-71-5275819; e-mail hoff@biophys.LeidenUniv.nl.

Department of Biophysics, Huygens Laboratory.

$\S$ Leiden Institute of Chemistry, Gorlaeus Laboratories.

${ }^{1}$ Abbreviations: A-branch, active electron transport branch; Bbranch, inactive electron transport branch; $\beta$-mutant, L(M214)H; DHW mutant, G(M203)D/L(M214)H/A(M260)W; $\mathrm{H}_{\mathrm{A}, \mathrm{B}}$, pheophytin primary electron acceptors; LDHW mutant, H(M182)L/G(M203)D/L(M214)H/ $\mathrm{A}(\mathrm{M} 260) \mathrm{W} ; \mathrm{P}$, primary electron donor; $\mathrm{Q}_{\mathrm{A}, \mathrm{B}}$, quinone secondary electron acceptors; $\mathrm{RC}$, reaction center.
}

and $C$. aurantiacus (4-6). Bylina et al. (2) showed for $R b$. capsulatus RCs that the red shift of $\mathrm{H}_{\mathrm{A}}$ with respect to $\mathrm{H}_{\mathrm{B}}$ is largely due to a glutamic acid residue in the L-subunit (L104 in Rb. sphaeroides), which forms a hydrogen bond to $\mathrm{H}_{\mathrm{A}}$. This residue is conserved in all purple bacterial RCs studied so far and in $C f$. aurantiacus. In Rps. viridis RCs, $\mathrm{H}_{\mathrm{A}}$ and $\mathrm{H}_{\mathrm{B}}$ can be readily distinguished by their $\mathrm{Q}_{\mathrm{Y}}$ absorption bands at 810 and $790 \mathrm{~nm}$, respectively $(5,6)$. After excitation of the primary electron donor $\mathrm{P}$ and subsequent electron transfer, a bleaching of the band at $810 \mathrm{~nm}$ but not of the band at $790 \mathrm{~nm}$ is observed, due to photoreduction of $\mathrm{H}_{\mathrm{A}}$ but not of $\mathrm{H}_{\mathrm{B}}$. For RCs of $R b$. sphaeroides, $R b$. capsulatus, and $C f$. aurantiacus the $\mathrm{Qx}_{\mathrm{x}}$ region is used to distinguish between $\mathrm{H}_{\mathrm{A}}$ and $\mathrm{H}_{\mathrm{B}}$, due to the better resolution of the absorption bands in this region. For these RCs a bleaching of the $\mathrm{H}_{\mathrm{A}}$ absorption band near $547 \mathrm{~nm}[R b$. sphaeroides and $R b$. capsulatus (7)] or $540 \mathrm{~nm}[C f$. aurantiacus (8)] is observed but not of the $\mathrm{H}_{\mathrm{B}}$ absorption band near $530 \mathrm{~nm}$.

The branching ratio of A- vs B-side electron transfer is not known exactly, but the upper limit for the yield of $\mathrm{P}^{+} \mathrm{H}_{\mathrm{B}}{ }^{-}$ is a few percent. A direct estimate of the branching ratio by comparing the extent of bleaching of the $\mathrm{H}_{\mathrm{A}}$ and $\mathrm{H}_{\mathrm{B}}$ absorption bands at room temperature is not possible because these absorption bands overlap. At cryogenic temperatures, where these bands are resolved, an upper limit of $\sim 5 \%$ for electron transfer to $\mathrm{H}_{\mathrm{B}}$ has been determined $(7-10)$. An estimate for the extent of $\mathrm{H}_{\mathrm{B}}$ bleaching near room temperature has been obtained by Heller et al. (11). They estimated electron transfer from $\mathrm{P} *$ to $\mathrm{H}_{\mathrm{B}}$ to occur with a time constant, $k_{\mathrm{B}}$, of $100 \mathrm{ps}$ in a $R b$. capsulatus $\mathrm{RC}$ mutant with impaired 
A-branch photochemistry. Since photoreduction of $\mathrm{H}_{\mathrm{A}}$ in wild-type RCs occurs with a time constant of $3 \mathrm{ps}$, a branching ratio $k_{\mathrm{A}} / k_{\mathrm{B}}$ of $\sim 30$ results for wild-type RCs, implying a yield of $3 \%$ for $\mathrm{P}^{+} \mathrm{H}_{\mathrm{B}}{ }^{-}$(11). Another method of determining the ratio of A- vs B-side electron transfer was used by Kellogg et al. (6). They studied the formation of $\mathrm{P}^{+} \mathrm{H}_{\mathrm{B}}{ }^{-}$in $\mathrm{RC}$ s that lacked $\mathrm{Q}_{\mathrm{B}}$ and in which $\mathrm{Q}_{\mathrm{A}}$ and $\mathrm{H}_{\mathrm{A}}$ were already reduced. From the measured yield of $\mathrm{P}^{+} \mathrm{H}_{\mathrm{B}}{ }^{-}$and the lifetime of $\mathrm{P}^{*}$ in $\mathrm{RCs}$ with reduced $\mathrm{Q}_{\mathrm{A}}$ and $\mathrm{H}_{\mathrm{A}}$ [20 ps (12)], the branching ratio $k_{\mathrm{A}} / k_{\mathrm{B}}$ was determined to be $\sim 200$.

It should be noted that assignment of the small absorbance changes that have been observed near $530 \mathrm{~nm}$ to photobleaching of $\mathrm{H}_{\mathrm{B}}$ is not unambiguous. For instance, charge separation along the A-branch may induce an electrochromic shift of the $\mathrm{H}_{\mathrm{B}} \mathrm{Q}_{\mathrm{X}}$ band or of the carotenoid absorption bands in the region of $\mathrm{H}_{\mathrm{B}} \mathrm{Q}_{\mathrm{X}}$ absorption (in the case of carotenoid containing RCs) $(8,11)$. For $C f$. aurantiacus $\mathrm{RCs}$ (with $\mathrm{H}_{\mathrm{B}}$ absorbing at $530 \mathrm{~nm}$ and $\mathrm{H}_{\mathrm{A}}$ at $540 \mathrm{~nm}$ ) it has been shown that the bleaching observed near $530 \mathrm{~nm}$, which is more pronounced than in $R b$. sphaeroides RCs, is (largely) correlated with electron transfer through the A-branch (8). Absorption at $530 \mathrm{~nm}$ of multiple photons at high light intensity can cause B-side electron transfer, at least in $R b$. sphaeroides (13).

Although photoreduction of $\mathrm{H}_{\mathrm{B}}$ is usually not observed after a single excitation of $\mathrm{P}$, Robert et al. (4) have shown that $\mathrm{H}_{\mathrm{B}}{ }^{-}$can be accumulated by illumination of RCs poised at low redox potentials in the presence of the redox mediator methyl viologen. The mechanism of this reaction is not clear, but the fact that $\mathrm{H}_{\mathrm{B}}{ }^{-}$can be photoaccumulated suggests $\mathrm{P}^{+} \mathrm{H}_{\mathrm{B}}{ }^{-}$is formed in low yields in a single flash and that its formation is not thermodynamically impossible.

The origin of the preferential use of the A-branch in charge separation is not known. It can be argued that not understanding why the B-branch is not used is tantamount to not understanding A-branch electron transfer. Many studies have been aimed at getting insight in unidirectionality in terms of current electron transfer theories, and many attempts have been made to promote electron transfer through the B-branch (reviewed in ref 7; see also refs 11 and 14-18). Ideally one would like to have a detailed set of data on both electron transfer through the A-branch and electron transfer through the B-branch in order to evaluate the different physical factors that govern the direction of electron transfer in the RC. Most work has been done by use of site-directed mutagenesis for changing purported key amino acids in either the A- or B-chain. In some other work pigment modification has been employed. Success has been limited so far to $\sim 35 \%$ B-chain transport (17). This situation has prompted us to further explore site-directed mutagenesis as a method to come to more strongly reduced A/B-branching ratios for electron transport in RCs of a purple bacterium.

In a previous article (16), we have described an RC triple mutant (labeled DHW) of Rb. sphaeroides with three mutations affecting charge separation through the A-branch. Two of these mutations, G(M203)D and L(M214)H, slow electron transfer through the A-branch. Due to the third mutation, $\mathrm{A}(\mathrm{M} 260) \mathrm{W}, \mathrm{Q}_{\mathrm{A}}$ is absent, leaving $\mathrm{Q}_{\mathrm{B}}$ as the only ubiquinone in the RC. Together, these mutations enable the study of $\mathrm{Q}_{\mathrm{B}}$ photoreduction via the B-branch, which is the same as in wild-type RCs. Although the lifetime of $\mathrm{P}^{*}$ in the DHW mutant was considerably longer than the $\mathrm{P}^{*}$ lifetime in wild-type $\mathrm{RCs}$, bleaching of the absorption band of $\mathrm{H}_{\mathrm{B}}$ could not be demonstrated (upper limit less than $5 \%$ of the bleaching of $\mathrm{H}_{\mathrm{A}}$ in wild-type $\mathrm{RCs}$ ). The state $\mathrm{P}^{+} \mathrm{Q}_{\mathrm{B}}{ }^{-}$was formed with a low yield $(<5 \%)$ and could not be photoaccumulated.

Recently, RCs of $R b$. sphaeroides were described in which the monomer bacteriochlorophyll $\mathrm{B}_{\mathrm{B}}$ was replaced by a bacteriopheophytin, $\Phi_{\mathrm{B}}$, due to the mutation H(M182)L (17). In the following, these RCs will be called $\Phi_{\mathrm{B}} \mathrm{RCs}$. In $\Phi_{\mathrm{B}}$ RCs B-branch electron transfer with a yield of $\sim 35 \%$ was reported, resulting in the formation of $\mathrm{P}^{+} \Phi_{\mathrm{B}}{ }^{-}$(17). Also recently, Kirmaier et al. (15) showed that when mutations impeding A-branch electron transfer in the $\mathrm{RC}$ of $R b$. capsulatus were combined with a mutation that presumably raises the $\mathrm{B}_{\mathrm{B}}{ }^{-} / \mathrm{B}_{\mathrm{B}}$ midpoint potential, these mutations cooperated to result in $\mathrm{P}^{+} \mathrm{H}_{\mathrm{B}}{ }^{-}$formation with a yield of $25 \%$. By analogy, replacement of $\mathrm{B}_{\mathrm{B}}$ with $\Phi_{\mathrm{B}}$ in the $R b$. sphaeroides $\mathrm{RCs}$ combined with mutations that (partially) impede Abranch electron transfer should lead to increased B-branch electron transfer. The quadruple mutant described in the present article was designed with this objective. It was constructed by introducing the mutation $\mathrm{H}(\mathrm{M} 182) \mathrm{L}$, resulting in the replacement of $\mathrm{B}_{\mathrm{B}}$ with $\Phi_{\mathrm{B}}$, in the DHW mutant that was described previously (16). In summary, the resulting quadruple mutant, LDHW, has the following mutations (see Figure 1): (1) $\mathrm{H}(\mathrm{M} 182) \mathrm{L}$, which results in the incorporation of a bacteriopheophytin molecule, $\Phi_{\mathrm{B}}$, for $\mathrm{B}_{\mathrm{B}}$; (2) G(M203)D, making the transfer of an electron from $\mathrm{P}^{*}$ to $\mathrm{B}_{\mathrm{A}}$ more difficult; (3) L(M214)H, which results in the incorporation of a bacteriochlorophyll molecule, $\beta$, instead of the bacteriopheophytin molecule $\mathrm{H}_{\mathrm{A}}$; (4) $\mathrm{A}(\mathrm{M} 260) \mathrm{W}$, leading to the rigorous exclusion of $\mathrm{Q}_{\mathrm{A}}$ from the reaction center $(19,20)$. The mutations G(M203)D and L(M214)H cooperate to slow electron transfer through the A-branch (16). The high yield of "wrong way" electron-transfer expected for the LDHW mutant and the presence of $\mathrm{Q}_{\mathrm{B}}$ as the sole quinone molecule would make this mutant a suitable system for studying photoreduction of $\mathrm{Q}_{\mathrm{B}}$ via the B-branch.

We find that (i) $\mathrm{P}^{*}$ decay is faster in LDHW RCs than in DHW RCs [which do not contain the H(M182)L mutation; see ref 16)]; (ii) the yield of B-branch electron transfer in LDHW RCs at room temperature is 35-45\%; (iii) the $\mathrm{Q}_{\mathrm{x}}$ absorption bands of both bacteriopheophytins of the B-branch are simultaneously (partially) bleached; (iv) the ratio of the magnitude of these bleachings remains constant with time; and (v) no significant $(\sim 1 \%)$ formation of $\mathrm{P}^{+} \mathrm{Q}_{\mathrm{B}}{ }^{-}$occurs, suggesting that electron transfer from $\mathrm{H}_{\mathrm{B}}{ }^{-}$to $\mathrm{Q}_{\mathrm{B}}$ is not efficient enough to compete with charge recombination processes.

\section{MATERIALS AND METHODS}

Bacterial Strains, Growth, Mutagenesis, and Isolation of the Reaction Center. We have used the mutagenesis system originally developed by Paddock et al. (21), with some minor modifications (16), to introduce mutations in the M subunit of the RC of $R b$. sphaeroides. Site-directed mutations in the pufM gene were made by the following codon changes: CAC $\rightarrow$ CTG $($ M182 H $\rightarrow$ L), GGT $\rightarrow$ GAC $($ M203 G $\rightarrow$ D), $\mathrm{CTG} \rightarrow \mathrm{CAC}(\mathrm{M} 214 \mathrm{~L} \rightarrow \mathrm{H})$, and $\mathrm{GCC} \rightarrow \mathrm{TGG}(\mathrm{M} 260 \mathrm{~A}$ $\rightarrow \mathrm{W})$. Cell growth and the procedure of isolating wild-type and mutant RCs were as described in ref 16. 

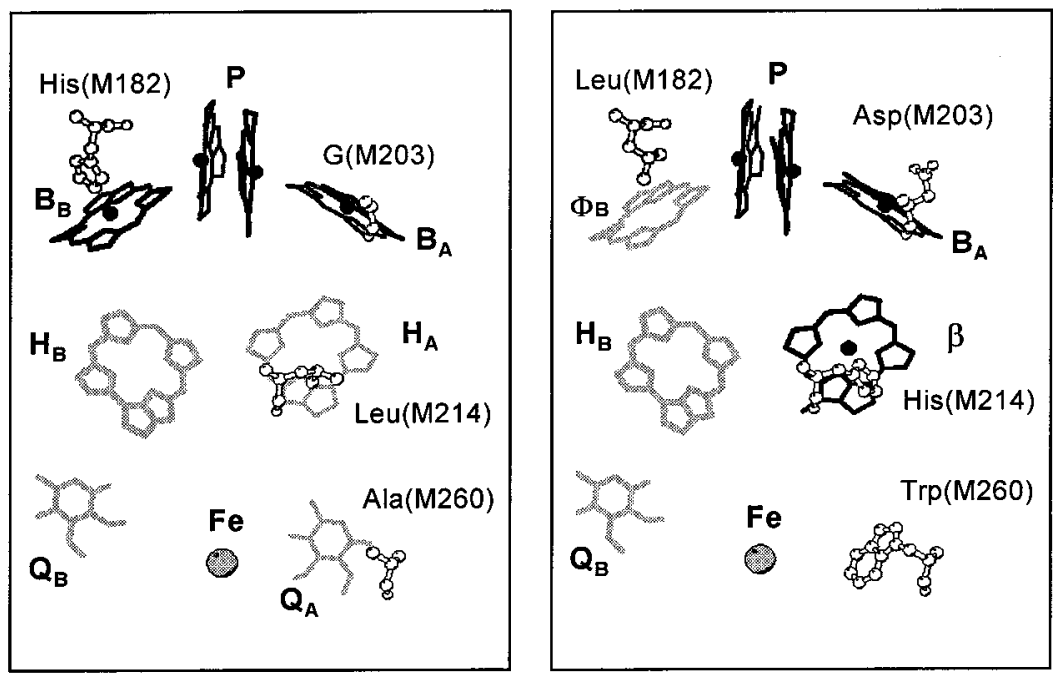

FIGURE 1: Schematic representation of the cofactors in wild-type RCs (left panel) and LDHW RCs (right panel). Amino acid residues that have been mutated are also shown. For clarity only the porphyrin rings of the bacteriochlorophylls and bacteriopheophytins are shown, and the carotenoid and isoprenoid tails of the quinones have been omitted. See text for details. After Ermler et al. (32), drawn with the Molscript program (33).

Steady-State Spectroscopy. Steady-state absorption spectroscopy was performed on a single-beam spectrophotometer (22). Glycerol was added to all samples used in lowtemperature experiments to a final concentration of $67 \%$ $(\mathrm{v} / \mathrm{v})$.

EPR Measurements. The electron paramagnetic resonance measurements were performed at $20 \mathrm{~K}$ with a home-built phase-sensitive homodyne combined pulsed and continuous wave $(\mathrm{cw})$ EPR spectrophotometer.

Charge Recombination and Yield of $P^{+} Q_{\mathrm{B}}{ }^{-}$. Formation and recombination of $\mathrm{P}^{+} \mathrm{Q}_{\mathrm{B}}{ }^{-}$at room temperature were studied by monitoring the bleaching of the $\mathrm{P}$ band near 865 $\mathrm{nm}$ following subsaturating filtered flash light provided by a xenon flash lamp. A home-built single-beam spectrophotometer $(23,24)$ was used to generate and record the kinetic data. The same apparatus was used to determine the yield of $\mathrm{P}^{+} \mathrm{Q}_{\mathrm{B}}{ }^{-}$formation. Here, subsaturating light from a tungsten halogen lamp filtered by an $860 \mathrm{~nm}$ interference filter was used to excite the $\mathrm{Q}_{\mathrm{Y}}$ band of $\mathrm{P}$ at $865 \mathrm{~nm}$. The amplitude of the resulting bleaching of the $\mathrm{Q}_{\mathrm{X}}$ band of $\mathrm{P}$ near $600 \mathrm{~nm}$ was measured as a function of the illumination time for samples of wild-type and mutant RCs with identical absorptions at $865 \mathrm{~nm}$. A 10-fold excess of $\mathrm{UQ}_{10}$ was added to the RCs to ensure full occupation of the $\mathrm{Q}_{B}$ site. The quantum yield for $\mathrm{P}^{+} \mathrm{Q}_{\mathrm{B}}{ }^{-}$formation in DHW RCs was determined by comparing the initial slopes obtained for wildtype and mutant RCs and with the assumption of a $100 \%$ quantum yield for $\mathrm{P}^{+} \mathrm{Q}_{\mathrm{B}}{ }^{-}$formation in wild-type RCs.

Picosecond Transient Absorption Spectroscopy. Timeresolved transient absorption difference measurements at room temperature were performed with a home-built amplified dye laser system with continuum generation and optical multichannel analyzer (OMA) detection, operating at $10 \mathrm{~Hz}$, described by Kennis et al. $(25,26)$. The time resolution was $600 \mathrm{fs}$. Excitation pulses were obtained by amplification of the continuum in a dye cell (LDS 867, Exciton). Wavelengths shorter than $850 \mathrm{~nm}$ were cut off with an RG850 filter (Melles Griot, Irvine, CA). Pump and probe pulses were polarized parallel to each other for better signal-to-noise. The influence of nonisotropic excitation of $\mathrm{P}$ and parallel probing of $\mathrm{H}_{\mathrm{A}}{ }^{-}$in WT RCs and $\mathrm{H}_{\mathrm{B}}{ }^{-}$and $\Phi_{\mathrm{B}}{ }^{-}$in the LDHW mutant can be calculated with the formalism of photoselection. With the assumption that the $\mathrm{Q}_{y}$ transitions are along the $N_{1}-N_{3}$ axes as given by the crystal structure and assuming identical molar extinction coefficients (see below), we find correction ratios $A_{\|}\left(\Phi_{\mathrm{B}}\right) / A_{\|}\left(\mathrm{H}_{\mathrm{A}}\right)=2.66$ and $A_{\|}\left(\mathrm{H}_{\mathrm{B}}\right) / A_{\|}\left(\mathrm{H}_{\mathrm{A}}\right)=1.11$, respectively, compared to ratios of unity for magic angle probing.

The samples contained $0.5 \mathrm{mM}$ terbutryn to inhibit $\mathrm{P}^{+} \mathrm{Q}_{\mathrm{B}}{ }^{-}$ formation and were kept in a moving cuvette (optical pathway $1 \mathrm{~mm}$ ) in order to avoid accumulation of photooxidized P. The absorbance was adjusted to $1.0 / \mathrm{mm}$ at the wavelength of interest. Excitation was in the primary donor band. Approximately $5-10 \%$ of the P absorption band was bleached per laser pulse.

\section{RESULTS AND DISCUSSION}

The combination of mutations G(M203)D and L(M214)H that inhibit A-branch electron transfer with the H(M182)L mutation that promotes B-branch electron transfer (17) was expected to result in a high yield of B-branch electron transfer, eventually leading to the formation of $\mathrm{P}^{+} \mathrm{Q}_{\mathrm{B}}{ }^{-}$ exclusively via the B-branch.

Absorption Spectra. Absorption spectra at $6 \mathrm{~K}$ of wildtype, DHW, and LDHW RCs are shown in Figure 2. The absorption spectra are different from each other because of the mutations that affect the cofactor composition of the RC. The absorption spectrum of the DHW mutant, which was described in detail in ref 16, differs from the wild type due to the replacement of the bacteriopheophytin $\mathrm{H}_{\mathrm{A}}$ with the $\beta$ bacteriochlorophyll molecule (Figure 1). In the absorption spectrum, this replacement is reflected by the disappearance of the $\mathrm{Qx}_{\mathrm{x}}$ band due to $\mathrm{H}_{\mathrm{A}}$ at $547 \mathrm{~nm}$, by the decreased amplitude of the band near $760 \mathrm{~nm}$ (which in wild-type RCs is due to the $\mathrm{Q}_{Y}$ transitions of both $\mathrm{H}_{\mathrm{A}}$ and $\mathrm{H}_{\mathrm{B}}$ but in the DHW mutant is due to the $\mathrm{Q}_{\mathrm{Y}}$ transition of $\mathrm{H}_{\mathrm{B}}$ only), and by the appearance of a new band at $784 \mathrm{~nm}$ due to the $\mathrm{QY}_{\mathrm{Y}}$ transition of $\beta$. The $\mathrm{H}(\mathrm{M} 182) \mathrm{L}$ mutation of the LDHW mutant results in the replacement of $B_{B}$ with the $\Phi_{B}$ bacteriopheophytin (17). As a consequence of this replace- 


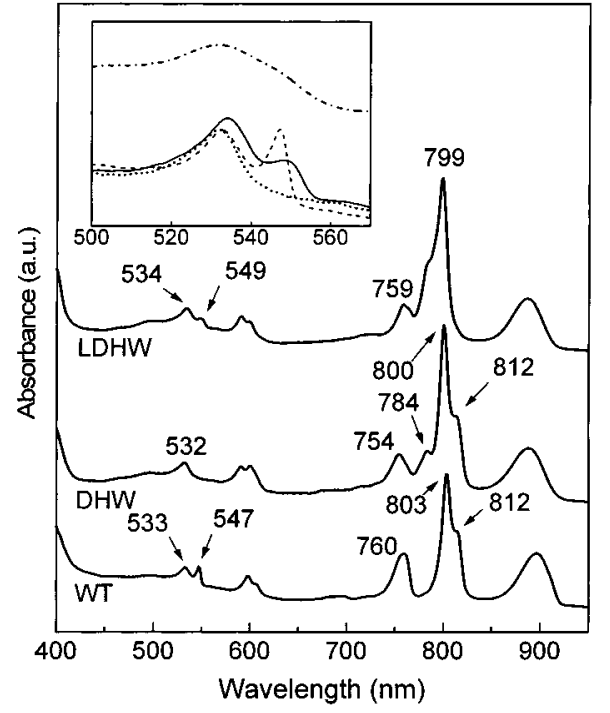

FIGURE 2: Low temperature $(6 \mathrm{~K})$ absorption spectra of wild-type (WT), DHW, and LDHW RCs. The inset shows the bacteriopheophytin $\mathrm{Qx}_{\mathrm{x}}$ absorption bands of WT RCs (---), DHW RCs (-*), and LDHW RCs $(-)$. The spectra were normalized to the same absorbance at the maximum of the $\mathrm{P}$ band. The upper curve $(-\cdot-$ ) in the inset represents the $\mathrm{Q}_{\mathrm{x}}$ absorption bands in LDHW RCs at room temperature.

ment, the absorption band at $812 \mathrm{~nm}$ due to the $\mathrm{Q}_{\mathrm{Y}}$ transition of $B_{B}$, which is visible as a shoulder of the $Q_{Y}$ absorption band of $\mathrm{B}_{\mathrm{A}}$ near $800 \mathrm{~nm}$ in the spectra of wild-type and DHW $\mathrm{RCs}$, is absent in the absorption spectrum of the LDHW mutant. Instead, a shoulder has now appeared at the blue side of the band near $800 \mathrm{~nm}$. We ascribe this shoulder to the $\mathrm{Q}_{\mathrm{Y}}$ absorption of both $\Phi_{\mathrm{B}}$ and $\beta$. As is described in ref 16 , the location of the $\mathrm{Q}_{\mathrm{Y}}$ absorption band of $\beta$ is quite variable. In the absorption spectrum of the $\mathrm{L}(\mathrm{M} 214) \mathrm{H}$ single mutant the absorption maximum is at $779 \mathrm{~nm}$, while it is at 775 and $784 \mathrm{~nm}$ in the absorption spectra of two other mutants studied in ref 16, the G(M203)D/L(M214)H (DH) and the G(M203)D/L(M214)H/A(M260)W (DHW) mutants, respectively. Considering this range of positions for the absorption maximum of $\beta$, it is likely that $\beta$ mostly contributes to the blue side of the shoulder and that $\Phi_{\mathrm{B}}$ contributes more to the red side of the shoulder. Replacement of $B_{B}$ with $\Phi_{B}$ also introduces a new band at $549 \mathrm{~nm}$. This band is due to the $\mathrm{Q}_{\mathrm{X}}$ transition of $\Phi_{\mathrm{B}}$. Its position is different from that of the $\mathrm{Q}_{\mathrm{X}}$ absorption of $\mathrm{H}_{\mathrm{B}}$ at $534 \mathrm{~nm}$ and resembles the position of the $\mathrm{H}_{\mathrm{A}} \mathrm{Q}_{\mathrm{X}}$ band at $547 \mathrm{~nm}$ in wildtype RCs. Although the positions of the $\mathrm{Qx}_{\mathrm{x}}$ absorption bands of $\Phi_{\mathrm{B}}$ and $\mathrm{H}_{\mathrm{A}}$ are similar, their shapes are quite different (Figure 2, inset). The absorption band of $\Phi_{\mathrm{B}}$ is much broader than that of $\mathrm{H}_{\mathrm{A}}$ (more like $\mathrm{H}_{\mathrm{B}}$ ), and the amplitude is lower. LDHW RCs have two bacteriopheophytins in the B-branch and none in the A-branch. The molar extinction coefficients of $H_{B}$ and $\Phi_{B}$ are largely the same as judged from the lowtemperature absorption spectra. B-branch electron transfer in LDHW RCs can be monitored by studying bleaching of the absorption bands due to the bacteriopheophytins. Furthermore, since the absorption maxima of the two bacteriopheophytins have different positions, it is possible to observe photoreduction of each of them separately.

Picosecond Transient Absorption Spectroscopy at Room Temperature. Picosecond transient absorption measurements were performed in the presence of terbutryn to prevent the

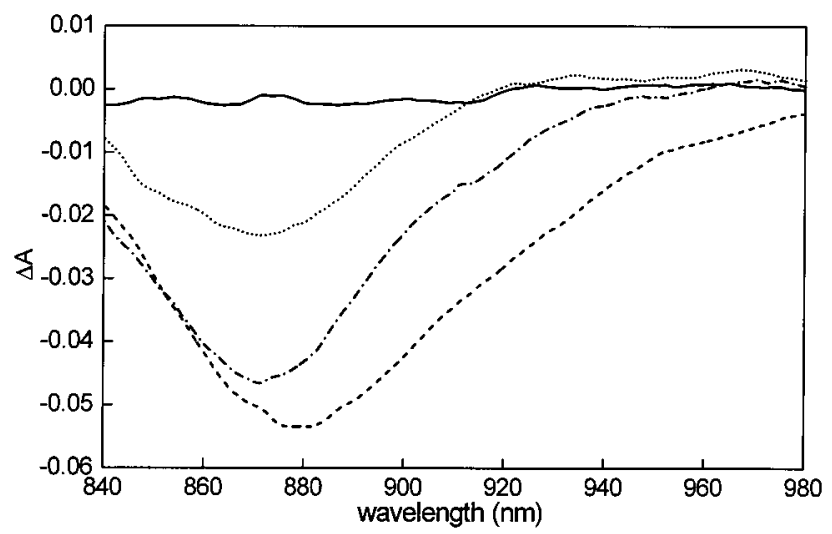

FIGURE 3: Transient absorption difference spectra at room temperature at the long-wavelength absorption band of P for LDHW RCs. Shown are spectra before excitation $(-)$ and at delay times of 1 ps (---), 8 ps $(-\cdot-)$, and 450 ps (-*).

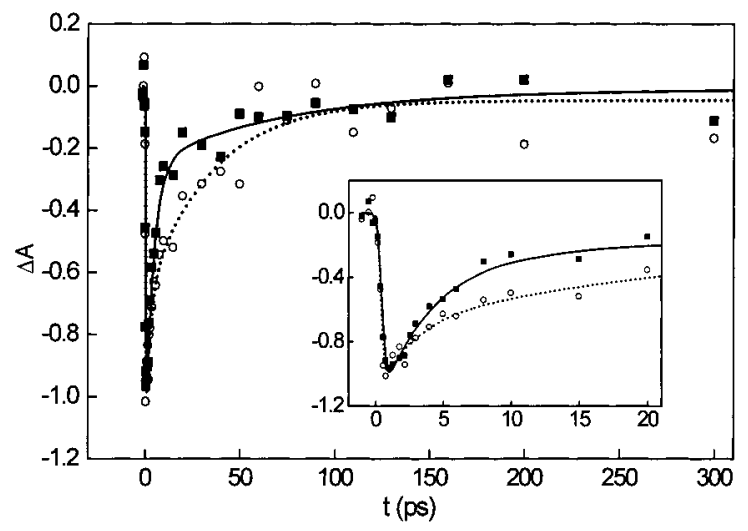

FIGURE 4: Kinetics of $\mathrm{P}^{*}$ decay at room temperature, averaged between 920 and $930 \mathrm{~nm}$. $(\mathrm{O}, \cdots)$ Transient absorption data and a biexponential fit obtained for DHW RCs; $(\boldsymbol{\square},-)$ data and a biexponential fit obtained for the LDHW mutant. The data were normalized to have identical initial bleachings of $\mathrm{P}$. The inset shows the data between 0 and 20 ps.

photoaccumulation of the long-lived $\mathrm{P}^{+} \mathrm{Q}_{\mathrm{B}}{ }^{-}$state with the laser system operating at $10 \mathrm{~Hz}$. Absorption difference spectra obtained for the LDHW mutant in the absorption band of $\mathrm{P}$ near $865 \mathrm{~nm}$ at several delay times are shown in Figure 3. Absorption changes in this region are due to bleaching of the $865 \mathrm{~nm}$ band on which stimulated emission of $\mathrm{P}^{*}$ between 870 and $1000 \mathrm{~nm}$ is superimposed. As in wildtype RCs, the stimulated emission in LDHW RCs decays as $\mathrm{P}^{*}$ disappears by charge separation. In wild-type RCs, charge separation in the presence of terbutryn leads to the formation of the state $\mathrm{P}^{+} \mathrm{Q}_{\mathrm{A}}{ }^{-}$. This state does not appreciably decay on the picosecond or nanosecond time scale. Thus, no $\mathrm{P}$ recovery is visible on these time scales and the bleaching near $865 \mathrm{~nm}$ persists. In contrast, in LDHW RCs charge separation does not lead to the formation of such relatively long-lived states, since these RCs contain neither $\mathrm{Q}_{\mathrm{A}}$ [due to the $\mathrm{A}(\mathrm{M} 260) \mathrm{W}$ mutation] nor $\mathrm{Q}_{\mathrm{B}}$ (due to the presence of terbutryn). Instead, relatively short-lived states are formed that recombine on the picosecond to nanosecond time scale and lead to recovery of $\mathrm{P}$ and hence to a decay of the bleaching near $865 \mathrm{~nm}$. In Figure 4 the $\mathrm{P}^{*}$ decay kinetics and fits for both DHW and LDHW RCs are shown. The fast component of $\mathrm{P}^{*}$ decay in LDHW RCs is about twice as large as that in DHW RCs. This is in keeping with the assumption that B-branch electron transfer is possible as an 


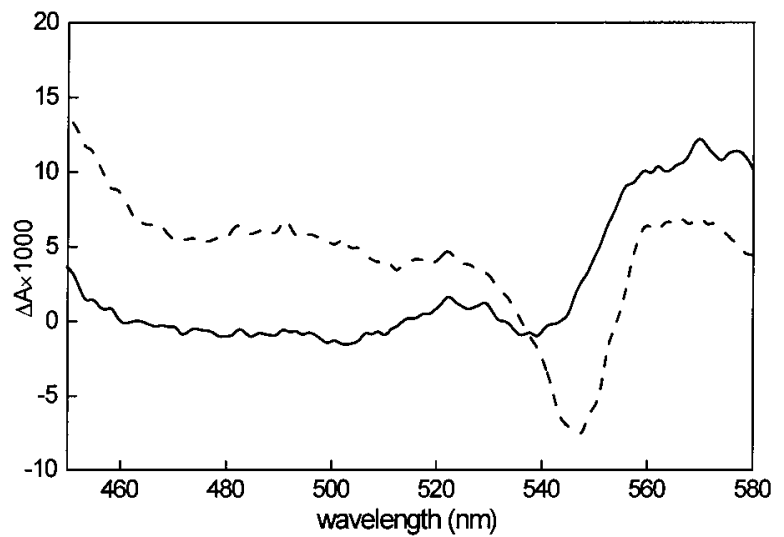

FIGURE 5: Absorption difference spectra at room temperature of wild-type and LDHW RCs in the $\mathrm{Q}_{\mathrm{x}}$ region where the bacteriopheophytins absorb. The bleaching at $545 \mathrm{~nm}$ in the spectrum for wild-type RCs after a delay time of $10 \mathrm{ps}$ (---) is due to photoreduction of $\mathrm{H}_{\mathrm{A}}$. The bleaching at $540 \mathrm{~nm}$ in LDHW RCs at a delay time of $30 \mathrm{ps}(-)$ is due to photoreduction of $\Phi_{B}$ and $H_{B}$, the bacteriopheophytins in the B branch of this mutant (see text for details). The spectra were normalized to have identical initial bleachings of $\mathrm{P}$.

extra, alternative channel for charge separation in LDHW RCs. For both RCs two exponential components are required to obtain an adequate fit. A biexponential fit yielded time constants of $2.5 \pm 0.8$ ps (40\%) and $36 \pm 5$ ps (60\%) for the DHW mutant, and for the LDHW mutant, time constants of $3.7 \pm 0.8 \mathrm{ps}(85 \%)$ and $63 \pm 7 \mathrm{ps}(15 \%)$. $\mathrm{P}^{*}$ decay also has been reported to be faster in $\Phi_{\mathrm{B}} \mathrm{RCs}$ [RCs that only have the H(M182)L mutation] than in wild-type RCs (17). Single-exponential fits of their $\mathrm{P}^{*}$ decays yielded time constants of 2.6 and 3.1 ps for $\Phi_{\mathrm{B}}$ and wild-type RCs, respectively.

Evidence for B-branch electron transfer in LDHW RCs is presented in Figure 5, where absorption difference spectra in the $\mathrm{Qx}_{\mathrm{x}}$ region of the bacteriopheophytins are shown for wild-type and LDHW RCs. In the wild-type spectrum a strong bleaching at $545 \mathrm{~nm}$ (due to photoreduction of $\mathrm{H}_{\mathrm{A}}$ ) is superimposed on a broad, essentially featureless absorption band. This broad absorption band is always present, at short as well as at longer delay times $(3,9,27)$, suggesting that it is associated with $\mathrm{P}^{*}$ as well as $\mathrm{P}^{+}$. A similar broad, featureless absorption band was observed for the DHW mutant at all delay times after $\mathrm{P}^{*}$ formation (16). For unknown reasons, for the LDHW mutant there is no such absorption increase in the 460-520 nm region of the difference spectrum, nor is it visible in the data presented for $\Phi_{\mathrm{B}} \mathrm{RCs}$ (17). There is some absorption, however, between 525 and $570 \mathrm{~nm}$. Superimposed on this absorption there is a trough near $540 \mathrm{~nm}$. The position of the trough corresponds to the position of the bleaching at $538 \mathrm{~nm}$ that has been found in $\Phi_{\mathrm{B}} \mathrm{RCs}$ (17). This bleaching was ascribed to photoreduction of $\Phi_{\mathrm{B}}$ and it was concluded that no further electron transfer to $\mathrm{H}_{\mathrm{B}}$ occurs in $\Phi_{\mathrm{B}} \mathrm{RCs}$. As will be shown below, low-temperature experiments with LDHW RCs provide evidence for simultaneous, partial bleaching of the absorption bands of both $\mathrm{H}_{\mathrm{B}}$ and $\Phi_{\mathrm{B}}$. At room temperature, where the $\mathrm{Q}_{\mathrm{X}}$ absorption bands of $\mathrm{H}_{\mathrm{B}}$ and $\Phi_{\mathrm{B}}$ are not resolved, only one negative band is visible, centered near $540 \mathrm{~nm}$.

Picosecond Transient Absorption Spectroscopy at $10 \mathrm{~K}$. Transient absorption difference spectra in the $\mathrm{Q}_{\mathrm{Y}}$ region at

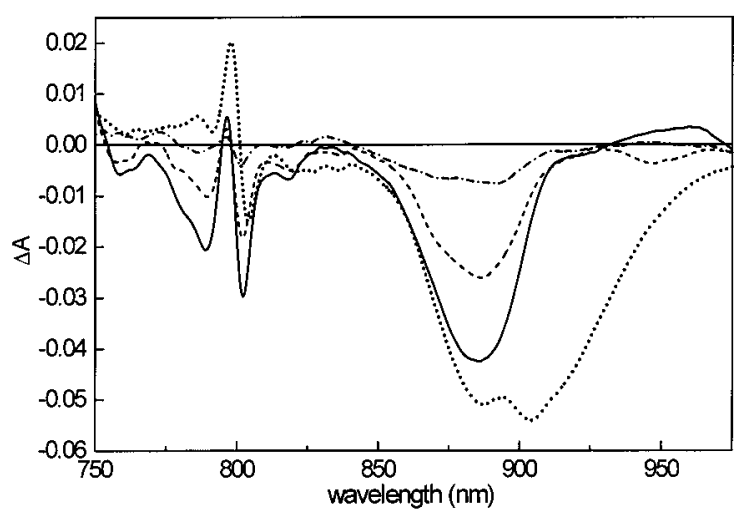

FIGURE 6: Absorption difference spectra in the $\mathrm{Q}_{\mathrm{Y}}$ region for LDHW RCs at $10 \mathrm{~K}$. The spectra were taken at delay times of 1 ps (*), 30 ps (-), 450 ps (--), and $1.9 \mathrm{~ns}(-\cdot-)$.

$10 \mathrm{~K}$ obtained for the LDHW mutant at several delay times are shown in Figure 6. The spectrum at a delay time of $1 \mathrm{ps}$ primarily represents the excited state of $\mathrm{P}$. There is a large bleaching near $890 \mathrm{~nm}$, where $\mathrm{P}$ absorbs. Superimposed on the red side of this bleaching is a band due to stimulated emission from $\mathrm{P}^{*}$. Signals around $800 \mathrm{~nm}$ are ascribed to changes in the excitonic interactions between $\mathrm{P}$ and $\mathrm{B}_{\mathrm{A}}(7)$, since $B_{B}$ has been replaced with $\Phi_{B}$, which absorbs near $790 \mathrm{~nm}$. The new feature near $790 \mathrm{~nm}$ may then reflect changes in the interaction between $\mathrm{P}$ and $\Phi_{\mathrm{B}}$. In the spectrum at $30 \mathrm{ps}$ the stimulated emission has largely disappeared due to charge separation. A strong bleaching has developed near $790 \mathrm{~nm}$, with a shoulder near $780 \mathrm{~nm}$. As discussed in an earlier section, both $\Phi_{\mathrm{B}}$ and $\beta$ contribute to the shoulder on the blue side of the band of $\mathrm{B}_{\mathrm{A}}$ near $800 \mathrm{~nm}$, with $\beta$ probably contributing more to the blue side of this shoulder. Accordingly, the strong bleaching near $790 \mathrm{~nm}$ in the absorption difference spectrum is likely due to bleaching of the $\Phi_{\mathrm{B}} \mathrm{Q}_{\mathrm{Y}}$ band, while the shoulder near $780 \mathrm{~nm}$ is due to bleaching of the $\beta \mathrm{Q}_{\mathrm{Y}}$ band. The absorption changes near $755 \mathrm{~nm}$ are related to $\mathrm{H}_{\mathrm{B}}$. Possible contributions in this region are a bandshift of the $\mathrm{H}_{\mathrm{B}} \mathrm{Q}_{\mathrm{Y}}$ band due to photoreduction of $\Phi_{\mathrm{B}}$ as well as bleaching of the $\mathrm{H}_{\mathrm{B}} \mathrm{Q}_{\mathrm{Y}}$ band due to its own photoreduction.

The shape of the spectra at $450 \mathrm{ps}$ and at $1.9 \mathrm{~ns}$ is largely the same as that of the $30 \mathrm{ps}$ spectrum, although the amplitudes of the absorption and bleaching maxima have decreased because some recombination of charge-separated states has occurred. These data suggest that the chargeseparated states in LDHW RCs, $\mathrm{P}^{+} \Phi_{\mathrm{B}}{ }^{-}, \mathrm{P}^{+} \mathrm{H}_{\mathrm{B}}{ }^{-}$, and $\mathrm{P}^{+} \beta^{-}$ (and possibly $\mathrm{P}^{+} \mathrm{B}_{\mathrm{A}}{ }^{-}$), decay with approximately the same time constants. This interpretation is consistent with the room-temperature data obtained for the DHW mutant, where the bleaching of $\mathrm{P}$ also has largely vanished after $1.9 \mathrm{~ns}$ (16). Recombination of $\mathrm{P}^{+} \Phi_{\mathrm{B}}{ }^{-}$in $\Phi_{\mathrm{B}} \mathrm{RCs}$ (at room temperature) was reported to occur with a time constant of $200 \mathrm{ps}$ (17).

Absorption difference spectra in the $\mathrm{Q}_{\mathrm{X}}$ region obtained at $10 \mathrm{~K}$ for the LDHW mutant are shown in Figure 7. Spectra taken at 25,30 , and $40 \mathrm{ps}(-)$ and at 400,500 , and $700 \mathrm{ps}$ ( $\cdots)$ were identical and have been averaged. As for the roomtemperature spectra, there is some positive absorption between 525 and $570 \mathrm{~nm}$. Superimposed on this absorption there are two troughs of about equal amplitude with minima at 534 and $549 \mathrm{~nm}$ that correspond to the positions of the Qx bands of $H_{B}$ and $\Phi_{B}$, respectively, and presumably are 


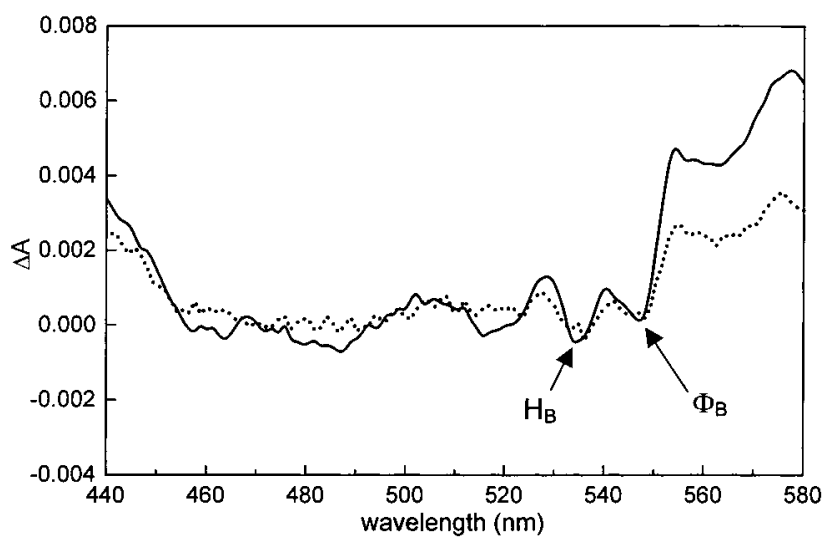

FIGURE 7: Absorption difference spectra at $10 \mathrm{~K}$ for LDHW RCs in the $\mathrm{Q}_{\mathrm{X}}$ region of the bacteriopheophytins. (-) Average of spectra at delay times of 25,30 , and $40 \mathrm{ps;} \mathrm{( \cdots )} \mathrm{average} \mathrm{of} \mathrm{spectra} \mathrm{at} \mathrm{delay}$ times of 400, 500, and $700 \mathrm{ps}$. Arrows indicate the positions of the bleachings of the bacteriopheophytins of the B branch in LDHW RCs.

due to (partial) bleaching of these bands. The shape of the difference spectra shown in Figure 7 at different delay times is essentially the same. Since the bleachings at 534 and 549 $\mathrm{nm}$ appear and disappear simultaneously, it is likely that they result from an equilibrium between the states $\mathrm{P}^{+} \Phi_{\mathrm{B}}{ }^{-}$and $\mathrm{P}^{+} \mathrm{H}_{\mathrm{B}}{ }^{-}$. The bleaching near $540 \mathrm{~nm}$ that has been observed at room temperature in the absorption difference spectra for $\Phi_{\mathrm{B}} \mathrm{RCs}$ and LDHW RCs probably represents overlapping bleachings due to the formation of $\mathrm{P}^{+} \Phi_{\mathrm{B}}{ }^{-}$and $\mathrm{P}^{+} \mathrm{H}_{\mathrm{B}}{ }^{-}$. Since the B-branch in our quadruple mutant is identical to that of the $\Phi_{\mathrm{B}}$ mutant, the conclusion of Katilius et al. (17) that B-branch electron transfer in $\Phi_{B}$ RCs is limited to the formation of $\mathrm{P}^{+} \Phi_{\mathrm{B}}{ }^{-}$(that is, there is no further electron transfer to $\mathrm{H}_{\mathrm{B}}$ ) likely needs revision.

B-Chain Electron Transport. When the extent of B-chain electron transport is determined from the bleaching near 540 $\mathrm{nm}$, it is important to assess whether it represents photoreduction of the two B-chain bacteriopheophytins in LDHW RCs or whether it is possibly (partly) due to bandshifts of $\mathrm{H}_{\mathrm{B}}$ and/or $\Phi_{\mathrm{B}}$ resulting from charged cofactors in the Aand/or B-chain. Since the shape of the broad new band between 520 and $570 \mathrm{~nm}$ is unknown, such assessment is not unambiguous. We have, however, a number of independent arguments that most of the absorption changes at 540 (room temperature) and 534 and $549 \mathrm{~nm}(10 \mathrm{~K})$ are indeed due to bleachings.

First, charge separation in the H(M182)L mutant is faster than in WT RCs (17), and in the LDHW mutant, faster than in the DHW mutant. This indicates that there is an extra channel for charge separation competing with the A-chain.

Second, the 30 ps spectrum of Figure 6 shows between 770 and $820 \mathrm{~nm}$, where $\beta$ and $\Phi_{\mathrm{B}}$ absorb, a strong absorbance decrease, not just one or more shifts. An absorbance change at $790 \mathrm{~nm}$ is also observed by Katilius et al. (17), whose mutant does not contain the $\beta$ pigment. The $\beta$ pigment shows a small absorbance at $784 \mathrm{~nm}$ (15, 16) and if bleached would contribute only little to the bleaching at $790 \mathrm{~nm}$. Since the band at $549 \mathrm{~nm}$ is clearly related to $\Phi_{\mathrm{B}}$, its change concomitant with the bleaching of the $790 \mathrm{~nm}$ band strongly suggests that this change is also a bleaching.

Third, we and others $(15,16)$ have not observed a shift of $\mathrm{H}_{\mathrm{B}}$ due to reduction of the $\mathrm{B}_{\mathrm{A}} \beta$ complex in the $\beta$-mutants.
Since there is no $\mathrm{H}_{\mathrm{A}}$ present in the LDHW mutant, a shift of $\mathrm{H}_{\mathrm{B}}$ due to $\mathrm{H}_{\mathrm{A}}{ }^{-}$as suggested in ref 8 for $C f$. aurantiacus RCs cannot occur. This purported shift followed the kinetics of $\mathrm{H}_{\mathrm{A}}{ }^{-}$and not of $\mathrm{P}^{+}$. Neither were there indications for a $\mathrm{P}^{+}$-induced shift of $\Phi_{\mathrm{B}}$ in the nanosecond difference spectrum of $\mathrm{Q}_{\mathrm{A}}$-containing $C f$. aurantiacus $\mathrm{RCs}$.

Fourth, a remaining shift mechanism would be a shift of the $\mathrm{Q}_{x}$ band of $\Phi_{\mathrm{B}}$ by $\mathrm{H}_{\mathrm{B}}{ }^{-}$or that of $\mathrm{H}_{\mathrm{B}}$ by $\Phi_{\mathrm{B}}{ }^{-}$. In that case at least half of the unresolved absorbance changes in the $\mathrm{Q}_{x}$ band region observed at room temperature (Figure 5) would be due to a bleaching of either $\Phi_{B}$ or $H_{B}$ or both. In view of the data in Figure 2 and Figure 6, we believe that in the difference spectrum of Figure 7 the feature at $549 \mathrm{~nm}$ represents a photoreduction. Then, the feature at $534 \mathrm{~nm}$ cannot be a band shift, because it lacks the derivative shape. This lack can no longer be explained by the assumption of two overlapping band shifts in opposite direction. We conclude that the two features are due to photoreduction. By inference, also the absorbance change at $540 \mathrm{~nm}$ in the spectrum of Figure 5 is then due to photoreduction of the two B-chain bacteriopheophytins.

For assessing the extent of B-chain activity, the broad new band in the 520-560 region was approximated by the tail of a broad Gaussian peaking at about $570 \mathrm{~nm}$ for LDHW RCs and by a straight line connecting the data at 520 and $570 \mathrm{~nm}$ for wild-type RCs (spectra taken under identical conditions and normalized at the initial $\mathrm{P}$ band bleaching due to $\mathrm{P}^{*}$ formation). The amplitude of the two bands at 534 and $549 \mathrm{~nm}$ in the low-temperature spectrum of Figure 7 is about the same. By inference, the measured amplitude of the contribution of the bleaching of $\Phi_{B}$ and $H_{B}$ is then also similar in the room-temperature spectrum of Figure 5. The ratio of the area between the baseline and the trough at $540 \mathrm{~nm}$ in the difference spectrum for LDHW RCs to the corresponding area at $545 \mathrm{~nm}$ for wild-type RCs (which corresponds to $100 \%$ A-chain electron transport) is an estimate for the relative bleaching of the bacteriopheophytin absorption bands in the A- and B-chain when the appropriate correction factors for parallel probing are taken into account (see Materials and Methods). We thus obtain a yield of B-branch electron transfer in LDHW RCs of 35-45\%.

We note that Katilius et al. (17) could only estimate the yield of B-branch charge separation in $\Phi_{\mathrm{B}} \mathrm{RCs}$ in an indirect way by virtue of the fact that the charge-separated state(s) in this branch recombine(s) with a time constant of $200 \mathrm{ps,}$ much faster than charge recombination of $\mathrm{P}^{+} \mathrm{Q}_{\mathrm{A}}{ }^{-}$or $\mathrm{P}^{+} \mathrm{H}_{\mathrm{A}}{ }^{-}$ in the A-branch, which typically occur with time constants of $100 \mathrm{~ms}$ and $\sim 10 \mathrm{~ns}$, respectively. In contrast, our determination of $35-40 \%$ for B-branch charge separation relies directly on the bleaching of the bacteriopheophytin(s) involved. Interestingly, a yield of $\sim 30 \%$ B-chain electron transport was obtained for the $\beta$-mutant of $R b$. capsulatus in which additionally the Tyr(M208), corresponding to Tyr(M210) in Rb. sphaeroides, was swapped with the symmetryrelated Phe(L181) (28). This result and ours suggest that the relative position of the energy levels of the ion pairs $\mathrm{P}^{+} \mathrm{B}_{\mathrm{A}}{ }^{-}$ and $\mathrm{P}^{+} \mathrm{B}_{\mathrm{B}}{ }^{-}$with respect to $\mathrm{P}^{*}$ is an important factor in determining the branching ratio.

$P^{+} Q_{\mathrm{B}}{ }^{-}$Formation at Room Temperature. $\mathrm{P}^{+} \mathrm{Q}_{\mathrm{B}}{ }^{-}$formation in LDHW RCs was studied by monitoring light-induced changes on the time scale of (milli)seconds at the absorption band of $\mathrm{P}$ at $865 \mathrm{~nm}$ at room temperature. Since $\mathrm{Q}_{\mathrm{B}}$ is usually 
largely lost during $\mathrm{RC}$ preparation, excess $\mathrm{UQ}_{10}$ (at least 10fold) was added to the $\mathrm{RCs}$ to repopulate the $\mathrm{Q}_{\mathrm{B}}$ site. Despite the high yield of $35-45 \%$ for B-branch electron transfer in the LDHW mutant, no significant $(\sim 1 \%)$ formation of $\mathrm{P}^{+} \mathrm{Q}_{\mathrm{B}}{ }^{-}$ could be observed. This contrasts with our experimental data for the DHW mutant, where electron transfer from $\mathrm{H}_{\mathrm{B}}$ to

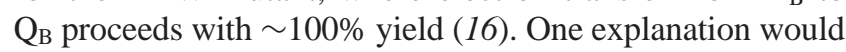
be that the $\mathrm{Q}_{\mathrm{B}}$ site in LDHW RCs is not populated, even after addition of extra $\mathrm{UQ}_{10}$. Thus either the H(M182)L mutation or the ensemble of mutations in LDHW RCs may prevent binding of $\mathrm{UQ}_{10}$ in the $\mathrm{Q}_{\text {в }}$ site. This is not very likely, however, since none of the mutations is located in the vicinity of the $\mathrm{Q}_{\mathrm{B}}$ binding pocket. Also, recent detailed X-ray crystallographic analysis of the $\mathrm{A}(\mathrm{M} 260) \mathrm{W}$ single mutant showed a high occupancy of the $\mathrm{Q}_{\mathrm{B}}$ site (29). Another explanation is that electron transfer from $\mathrm{H}_{\mathrm{B}}{ }^{-}$to $\mathrm{Q}_{\mathrm{B}}$ cannot compete with recombination between $\left(\Phi_{\mathrm{B}}, \mathrm{H}_{\mathrm{B}}\right)^{-}$and $\mathrm{P}^{+}$. Indeed, recombination between $\left(\Phi_{\mathrm{B}}, \mathrm{H}_{\mathrm{B}}\right)^{-}$and $\mathrm{P}^{+}$occurs with a time constant of $\sim 200$ ps (17) and thus is much faster then what would be expected for recombination between $\mathrm{H}_{\mathrm{B}}{ }^{-}$ and $\mathrm{P}^{+}\left(\sim 10 \mathrm{~ns}\right.$ by anology with $\mathrm{P}^{+} \mathrm{H}_{\mathrm{A}}{ }^{-}$recombination in the A-branch of wild-type RCs).

We may estimate the rate of electron transfer from $\left(\Phi_{\mathrm{B}}, \mathrm{H}_{\mathrm{B}}\right)^{-}$to $\mathrm{Q}_{\mathrm{B}}$ in the LDHW mutant by considering the time constant of charge recombination of the $\left(\mathrm{P}^{+} \Phi_{\mathrm{B}}{ }^{-}\right.$, $\mathrm{P}^{+} \mathrm{H}_{\mathrm{B}}{ }^{-}$) states in the B-branch, about $200 \mathrm{ps}$ (17), and the yields of the formation of these states and that of $\mathrm{P}^{+} \mathrm{Q}_{\mathrm{B}}{ }^{-}$. Since the mixture of the states $\mathrm{P}^{+} \Phi_{\mathrm{B}}{ }^{-}$and $\mathrm{P}^{+} \mathrm{H}_{\mathrm{B}}{ }^{-}$is formed with a yield of $35-45 \%$ and since $\mathrm{P}^{+} \mathrm{Q}_{\mathrm{B}}{ }^{-}$is formed with a yield of $\sim 1 \%$, electron transfer from the states $\mathrm{P}^{+} \Phi_{\mathrm{B}}{ }^{-}$and $\mathrm{P}^{+} \mathrm{H}_{\mathrm{B}}{ }^{-}$to $\mathrm{Q}_{\mathrm{B}}$ must be $\sim 40$ times slower than charge recombination of these states, implying a time constant of $\sim 10$ ns for electron transfer to $\mathrm{Q}_{\mathrm{B}}$. Thus electron transfer to $\mathrm{Q}_{\mathrm{B}}$ in the LDHW mutant is much slower than electron transfer from $\mathrm{H}_{\mathrm{A}}$ to $\mathrm{Q}_{\mathrm{A}}$ in the A-branch of wild-type RCs. One explanation may be that the $\mathrm{Q}_{B}$ binding pocket differs from that of $\mathrm{Q}_{\mathrm{A}}$. For instance, Stilz et al. (30) have observed that in Rb. capsulatus the mutation W(M250)F decreases the rate of electron transfer from $\mathrm{H}_{\mathrm{A}}{ }^{-}$to $\mathrm{Q}_{\mathrm{A}}$ by a factor of 4 . This suggests that $\mathrm{M} 250 \mathrm{~W}$, and its analogue $\mathrm{M} 252 \mathrm{~W}$ in $R b$. sphaeroides, acts as a superexchange conduit for electron transfer in the A-chain. In the B-chain the symmetry-related residue of $\mathrm{M} 252 \mathrm{~W}$ is a phenylalanine. Another explanation is that, in LDHW RCs, electron transfer to $\mathrm{Q}_{B}$ is not purely from $\mathrm{H}_{\mathrm{B}}{ }^{-}$but from $\left(\Phi_{\mathrm{B}}, \mathrm{H}_{\mathrm{B}}\right)^{-}$. This leads to a larger (average) electron-transfer distance and a resulting slowing down of the electron transfer as described by nonadiabatic electron transfer theory.

Photoaccumulation of $P^{+} Q_{\mathrm{B}}{ }^{-}$at $20 \mathrm{~K}$. Although $\mathrm{P}^{+} \mathrm{Q}_{\mathrm{B}}{ }^{-}$ in LDHW RCs is formed with a low yield of $\sim 1 \%$, presumably due to fast recombination of early intermediates in the charge separation sequence, prolonged illumination of these RCs should result in a appreciable population of the long-lived $\mathrm{P}^{+} \mathrm{Q}_{\mathrm{B}}{ }^{-}$state. This state was found to decay with a time constant of several seconds in DHW RCs (15). We could not photoaccumulate the $\mathrm{P}^{+} \mathrm{Q}_{\mathrm{B}}{ }^{-}$state under continuous illumination at $20 \mathrm{~K}$, as evidenced by our inability to detect the EPR signal due to $\mathrm{Q}_{\mathrm{B}}{ }^{-}$. Previously, we were also unable to detect photoaccumulation of $\mathrm{P}^{+} \mathrm{Q}_{\mathrm{B}}{ }^{-}$in DHW RCs (16).

Interestingly, $\mathrm{Q}_{B}$ in the $\mathrm{A}(\mathrm{M} 260) \mathrm{W}$ mutant is located in a proximal site relative to the non-heme iron, in contrast to
$\mathrm{Q}_{\mathrm{B}}$ in wild-type RCs, which is located in a distal position displaced by about $6 \AA$ in the direction of $\mathrm{H}_{\mathrm{B}}(31)$. Assuming that, unlike electron transfer from $\mathrm{H}_{\mathrm{A}}{ }^{-}$to $\mathrm{Q}_{\mathrm{A}}$ in its (proximal) site, $\mathrm{H}_{\mathrm{B}}{ }^{-}$cannot transfer electrons to $\mathrm{Q}_{\mathrm{B}}$ in the proximal position, this observation would explain our inability to photoaccumulate $\mathrm{P}^{+} \mathrm{Q}_{\mathrm{B}}{ }^{-}$in both the LDHW and the DHW mutants. At room temperature $\mathrm{Q}_{\text {В }}$ may move freely between the distal and proximal sites, whereas it may be frozen preferentially at the proximal site at $20 \mathrm{~K}$. These assumptions may explain why electron transfer from $\mathrm{H}_{\mathrm{B}}{ }^{-}$to $\mathrm{Q}_{\mathrm{B}}$ in DHW RCs occurs with a $100 \%$ yield at room temperature while no photoaccumulation occurs at $20 \mathrm{~K}$. The same reasoning holds for LDHW RCs, with the extra argument that electron transfer to $\mathrm{Q}_{\mathrm{B}}$ is by now much impaired as compared to DHW RCs (see above). As the distances between $\mathrm{H}_{\mathrm{A}}$ and $\mathrm{Q}_{\mathrm{A}}$, and between $\mathrm{H}_{B}$ and $\mathrm{Q}_{B}$ in the proximal position, are about the same, the difference in transfer rate is likely due to a difference in reorganization energy.

We note that the B-branch of LDHW RCs has an analogue in an RC mutant of Rps. viridis (32). In this RC mutant, $\mathrm{B}_{\mathrm{A}}$ is replaced by a bacteriopheophytin molecule, which we shall call $\Phi_{\mathrm{A}}$. Thus, this mutant has an A-branch that contains two bacteriopheophytins $\left(\Phi_{\mathrm{A}}\right.$ and $\left.\mathrm{H}_{\mathrm{A}}\right)$, whereas in $\Phi_{\mathrm{B}}$ and LDHW RCs the B-branch contains two bacteriopheophytins. In Rps. viridis $\Phi_{\mathrm{A}} \mathrm{RCs}$, charge separation results in a mixture of the states $\mathrm{P}^{+} \Phi_{\mathrm{A}}{ }^{-}$and $\mathrm{P}^{+} \mathrm{H}_{\mathrm{A}}{ }^{-}$. Subsequent $\mathrm{P}^{+} \mathrm{Q}_{\mathrm{A}}{ }^{-}$formation occurs with a yield of $50 \%$, whereas ground-state recovery of $\mathrm{P}$ accounts for the remaining $50 \%$. Both decays occur with a time constant of $140 \mathrm{ps}$ (32). Thus, the time constant for electron transfer from $\mathrm{P}^{+} \Phi_{\mathrm{A}}{ }^{-}$and $\mathrm{P}^{+} \mathrm{H}_{\mathrm{A}}{ }^{-}$to $\mathrm{Q}_{\mathrm{A}}$ is similar to the time constant for electron transfer from $\mathrm{H}_{\mathrm{A}}$ to $\mathrm{Q}_{\mathrm{A}}$ in wild-type RCs [200 ps (7)] and much smaller than the time constant of $10 \mathrm{~ns}$ for electron transfer from $\mathrm{P}^{+} \Phi_{\mathrm{B}}{ }^{-}$ and $\mathrm{P}^{+} \mathrm{H}_{\mathrm{B}}{ }^{-}$to $\mathrm{Q}_{\mathrm{B}}$ in LDHW RCs.

\section{CONCLUSIONS}

By combining mutations that impede A-branch electron transfer with a mutation that facilitates electron transfer through the B-branch, an RC mutant was created in which 35-45\% B-branch electron transfer occurs. This is the highest yield reported so far. The B-branch of the mutant contains two monomeric bacteriopheophytin molecules, $\Phi_{\mathrm{B}}$ and $\mathrm{H}_{\mathrm{B}}$. Low-temperature transient absorption studies show that charge separation through the B-branch leads to an equilibrium between $\mathrm{P}^{+} \Phi_{\mathrm{B}}{ }^{-}$and $\mathrm{P}^{+} \mathrm{H}_{\mathrm{B}}{ }^{-}$. Further electron transfer to $\mathrm{Q}_{\mathrm{B}}$ occurs with a very low yield $(\sim 1 \%)$. We conclude that electron transfer from $\mathrm{P}^{+} \Phi_{\mathrm{B}}{ }^{-}$and $\mathrm{P}^{+} \mathrm{H}_{\mathrm{B}}{ }^{-}$to $\mathrm{Q}_{\mathrm{B}}$ cannot compete with charge recombination.

\section{ACKNOWLEDGMENT}

We are indebted to Dr. I. V. Borovykh for carrying out the EPR experiments and to A. H. M. de Wit for his help in growing the bacteria.

\section{REFERENCES}

1. Zinth, W., Sander, M., Dobler, J., Kaiser, W., and Michel, H. (1985) in Antennas and reaction centers of photosynthetic bacteria (Michel-Beyerle, M.-E., Ed.) pp 97-102, SpringerVerlag, Berlin and New York.

2. Bylina, E. J., Kirmaier, C., McDowell, L., Holten, D., and Youvan, D. C. (1988) Nature 336, 182-184. 
3. Kirmaier, C., Gaul, D., DeBey, R., Holten, D., and Schenck, C. C. (1991) Science 251, 922-927.

4. Robert, B., Lutz, M., and Tiede, D. M. (1985) FEBS Lett. 183, 326-330.

5. Tiede, D. M. (1987) Photochem. Photobiol. Suppl. 45, 4242.

6. Kellogg, E. C., Kolaczkowski, S., Wasielewski, M. R., and Tiede, D. M. (1989) Photosynth. Res. 22, 47-59.

7. Woodbury, N. W., and Allen, J. P. (1995) in Anoxygenic photosynthetic bacteria (Blankenship, R. E., Madigan, M. T., and Bauer, C. E., Eds.) pp 527-557, Kluwer Academic Publishers, Dordrecht, The Netherlands.

8. Aumeier, W., Eberl, U., Ogrodnik, A., Volk, M., Scheidel, G., Feick, R., Plato, M., and Michel-Beyerle, M.-E. (1990) in Current Research in Photosynthesis (Baltscheffsky, M., Ed.) Vol. I, pp 133-136, Kluwer Academic Publishers, Dordrecht, The Netherlands.

9. Kirmaier, C., Holten, D., and Parson, W. W. (1985) Biochim. Biophys. Acta 810, 33-48.

10. Bixon, M., Jortner, J., Michel-Beyerle, M.-E., and Ogrodnik, A. (1989) Biochim. Biophys. Acta 977, 273-286.

11. Heller, B. A., Holten, D., and Kirmaier, C. (1995) Science 269, 940-945.

12. Holten, D., Windsor, M. W., Parson, W. W., and Thornber, J. P. (1978) Biochim. Biophys. Acta 501, 112-126.

13. Lin, S., Jackson, J. A., Taguchi, A. K. W., and Woodbury, N. W. (1999) J. Phys. Chem. B 103, 4757-4763.

14. Kolbasov, D., and Scherz, A. (2000) J. Phys. Chem. B 104, 1802-1809.

15. Kirmaier, C., Weems, D., and Holten, D. (1999) Biochemistry $38,11516-11530$.

16. de Boer, A. L., Neerken, S., de Wijn, R., Permentier, H. P., Gast, P., Vijgenboom, E., and Hoff, A. J. (2001) Photosynth. Res. (in press).

17. Katilius, E., Turanchik, T., Lin, S., Taguchi, A. K. W., and Woodbury, N. W. (1999) J. Phys. Chem. B 103, 7386-7389.

18. Laible, P. D., Kirmaier, C., Holten, D., Tiede, D. M., Schiffer, M., and Hanson, D. K. (1998) in Photosynthesis: Mechanisms and Effects (Garab, G., Ed.) Vol. II, pp 849-852, Kluwer Academic Publishers, Dordrecht, The Netherlands.

19. Ridge, J. P., van Brederode, M. E., Goodwin, M. G., van Grondelle, R., and Jones, M. R. (1999) Photosynth. Res. 59, 9-26.
20. McAuley, K. E., Fyfe, P. K., Ridge, J. P., Isaacs, N. W., Cogdell, R. J., and Jones, M. R. (1999) Proc. Natl. Acad. Sci. U.S.A. 96, 14706-14711.

21. Paddock, M. L., Rongey, S. H., Feher, G., and Okamura, M. Y. (1989) Proc. Natl. Acad. Sci. U.S.A. 86, 6602-6606.

22. Otte, S. C. M. (1992) Dissertation, Leiden University, Leiden, The Netherlands.

23. Visser, J. W. M. (1975) Dissertation, Leiden University, Leiden, The Netherlands.

24. Shochat, S., Gast, P., Hoff, A. J., Boender, G. J., van Leeuwen, S., van Liemt, W. B. S., Vijgenboom, E., Raap, J., Lugtenburg, J., and de Groot, H. J. M. (1995) Spectrochim. Acta A 51, $135-144$.

25. Kennis, J. T. M., Streltsov, A. M., Aartsma, T. J., Nozawa, T., and Amesz, J. (1996) J. Phys. Chem. 100, 2438-2442.

26. Kennis, J. T. M., Streltsov, A. M., Permentier, H., Aartsma, T. J., and Amesz, J. (1997) J. Phys. Chem. B 101, 83698374.

27. Franken, E. M., Shkuropatov, A. Y., Francke, C., Neerken, S., Gast, P., Shuvalov, V. A., Hoff, A. J., and Aartsma, T. J. (1997) Biochim. Biophys. Acta 1319, 242-250.

28. Kirmaier, C., He, H., and Holten, D. (2001) Biochemistry 40, $12132-12139$.

29. McAuley, K. E., Fyfe, P. K., Ridge, J. P., Cogdell, R. J., Isaacs, N. W., and Jones, M. R. (2000) Biochemistry 39, 1503215043 .

30. Stilz, H. U., Finkele, U., Holzapfel, W., Lauterwasser, C., Zinth, W., and Oesterhelt, D. (1994) Eur. J. Biochem. 223, 233-242.

31. Stowell, M. H., McPhillips, T. M., Rees, D. C., Soltis, S. M., Abresch, E., and Feher, G. (1997) Science 276, 812-816.

32. Arlt, T., Dohse, B., Schmidt, S., Wachtveitl, J., Laussermair, E., Zinth, W., and Oesterhelt, D. (1996) Biochemistry 35, 9235-9244.

33. Ermler, U., Fritzsch, G., Buchanan, S. K., and Michel, H. (1994) Structure 2, 925-936.

34. Kraulis, P. J. (1991) Appl. Crystallogr. 24, 946-950.

BI011450M 